\title{
Journal Club: Diffusion-Weighted MRI in Transient Global Amnesia and Its Diagnostic Implications
}

Daniel Talmasov, MD, and Arjun V. Masurkar, MD, PhD

Neurology ${ }^{\circledR}$ 2021;96:e2138-e2140. doi:10.1212/WNL.0000000000011352
Correspondence

Dr. Talmasov

daniel.talmasov@

nyulangone.org

The term transient global amnesia (TGA) was introduced by C. Miller Fisher and Raymond D. Adams in 1958 to describe a condition characterized by the abrupt onset of dense anterograde amnesia, followed by a return to normal cognition after a number of hours. ${ }^{1}$ TGA's underlying pathogenic mechanism remains a matter of debate, ${ }^{2}$ but transient dysfunction of brain regions deputed to memory, especially the hippocampus, appears to play a central role. ${ }^{2}$ While TGA is associated with delayed appearance (24-48 hours from symptom onset) of hippocampal lesions on diffusion-weighted imaging (DWI) magnetic resonance studies, ${ }^{3}$ diagnosis remains completely clinical, is based on diagnostic criteria established by Hodges and Warlow in 1990, 4,5 and requires either direct observation of transient anterograde amnesia by a clinician or collateral from a capable observer who witnessed the episode.

In this retrospective observational study, Szabo et al. ${ }^{6}$ propose the use of hippocampal DWI as an adjunctive role to history and examination in cases of low clinical diagnostic certainty: patients in whom TGA is suspected, but for whom the attack was neither observed by a clinician nor can be corroborated by a reliable observer.

\section{Hypothesis and Design}

The authors' hypothesis was that hippocampal DWI lesions can be used as a diagnostic criterion for TGA. They stratify the study population into those patients with high diagnostic certainty of TGA and those of low diagnostic certainty-patients in whom a diagnosis TGA is suspected, but the potential amnestic episode was not witnessed by an outside observer, and thus not strictly diagnosable by the Hodges and Warlow criteria. While DWI abnormalities on MRI have been observed in patients with TGA for over 2 decades, it is unclear in what situations DWI is diagnostically useful, and thus the use of MRI in TGA diagnosis has yet to be operationalized. If a positive diagnostic role of DWI in TGA were to be validated, it has the potential to be of greatest effect in supporting a diagnosis for patients who present after an unwitnessed potential amnestic episode. The validity of the authors' hypothesis that DWI lesions can be used as a diagnostic criterion for TGA is contingent on the assumption that diffusion-restricting hippocampal lesions (on diffusion-weighted MRI specifically protocoled with thin slices through the mesial temporal lobes) must be rare in control populations. This is important, as TGAassociated hippocampal lesions and isolated punctate hippocampal infarctions are indistinguishable on MRI, ${ }^{7}$ and thus a rigorous comparison to appropriately protocoled control scans would be necessary to rule out the possibility of lesions being incidental. A prior study ${ }^{3}$ found that $84 \%$ of 31 consecutive patients diagnosed with high diagnostic certainty TGA (episode witnessed by an outside observer) showed evidence of diffusion-restricting lateral hippocampal lesions on DWI. The authors performed a retrospective observational cohort study, which is in principle is a feasible means of testing the hypothesis, but limited in this study by a lack of age-matched normal controls. 


\section{Methods}

Authors analyzed demographic, clinical, and MRI data of 390 patients diagnosed with TGA in a prospectively collected database of patients treated at University Medical Centre Manheim at Heidelberg University between 1999 and 2018. All patients included had cranial MRI including a dedicated DWI protocol parallel to the long axis of the hippocampus, which was optimized for the detection of DWI lesions associated with TGA. The spatial distribution of DWI lesions and their temporal relationship to the reported time of TGA symptom onset was evaluated, as was the relationship of DWI-positive lesions to the degree of diagnostic certainty with which the TGA diagnosis was made according to the patient's history. Patients in whom an alternative diagnosis to TGA was considered on the basis of additional symptoms or in whom another diagnosis was confirmed on diagnostic testing were excluded.

\section{Results}

DWI-positive lesions were detected in 272 of 390 (70.6\%) patients diagnosed with TGA in the Heidelberg cohort, including 76 patients (69.1\%) among those 110 patients in whom TGA was diagnosed with lower diagnostic certainty (amnesia witnessed by a layperson or self-reported). DWIpositive lesions were most likely to be detected 12-24 hours after symptom onset, with $93 \%$ of detectable DWI lesions evident upon scans conducted during this time interval. The majority of patients in this cohort presented to the emergency department (ED) during their amnestic episode (280/390, or $71.8 \%)$, allowing for direct clinical diagnosis by Hodges and Warlow's diagnostic criteria. Many others (98/390, or 25.1\%) of those diagnosed with TGA during this 10 -year interval were asymptomatic at time of presentation but had history available from a reliable observer who was present during the patient's amnestic episode. The remaining 12 patients $(3.1 \%)$ presented for a self-reported memory gap but were asymptomatic in the ED and did not have witness corroboration.

The statistical analyses employed by the authors are appropriate, with distributions of continuous variables between groups compared with Student $t$ test and distributions of categorical variables compared using $\chi^{2}$ test for large cell sizes and Fisher exact test for smaller cell sizes.

\section{Interpretation}

A major limitation of the study is a lack of formal controls. Without demonstrating it in a control population, the authors implicitly assume that hippocampal abnormalities are very rare in the general population, and thus can be attributed to TGA in patients with relevant symptoms. Although this seems to be a fair assumption, it has not been demonstrated in controlled studies. This limits our ability to interpret the significance of the DWI abnormalities detected-namely, what percentage are attributable to TGA vs an incidental finding in the normal population. More curious is the authors' finding, in 11 patients (2.8\% of the cohort), of multiple small extrahippocampal lesions-a phenomenon the authors compare to "ischemic amnesia," a previously reported rare radiographic finding postulated to be associated with postembolic amnesia. ${ }^{8}$ An important point to be made, however, is that while this study lacks an asymptomatic control group, many patients underwent multiple MRI scans at different time points, opening the possibility of patients being used as their own controls, with the understanding that new lesions that temporally correlate with emergence of TGA symptoms can be considered markers of an underlying pathophysiologic process. The authors present aggregated data in figure 2 from 187 patients (46.3\% of their cohort) in whom the precise time of onset of TGA symptoms was known and demonstrate a temporal pattern supporting the hypothesis that DWI-positive hippocampal lesions appear following a delay (12-24 hours) from symptom onset. This cannot be proven in the authors' group of greatest interest, however-the group of patients in whom time of TGA onset is unknown, or who present following a subjective amnestic episode without collateral history from a reliable observer. Given that statistical methods exist for evaluating the efficacy of a diagnostic test in absence of a gold standard diagnosis for all or some participants in a research study, the authors' conclusions may have been strengthened by adjusting for this limitation. ${ }^{9} \mathrm{~A}$ controlled study using the same imaging protocols in patients without a history of TGA-like symptoms would be useful in contextualizing the significance of these lesions and definitively demonstrating their association with TGA. Another limitation of the study is that 24-hour ambulatory EEG was not used ${ }^{10}$; this would have been useful in ruling out transient epileptic amnesia, particularly in patients in the lower diagnostic certainty group.

Despite these limitations, the authors' finding that DWI-positive hippocampal lesions were present in $76(69.1 \%)$ of 110 patients with a presumed episode of TGA but in whom the episode was not directly observed by the diagnosing clinician has clinical import. This finding supports the existing practice, advanced by Hodges and Warlow, ${ }^{4,5}$ of diagnosing those patients who present after resolution of the amnestic period but with collateral history of an amnestic event from a witness with TGA. More importantly, these results support expending diagnostic criteria for TGA to include asymptomatic patients who present with subjective report of a discrete amnestic gap with no direct collateral from witnesses (12 patients of 390, or 3.1\% of this sample) if their MRI reveals new diffusion-restricting hippocampal lesions. This can readily be applied to practice as hippocampal-sensitive DWI protocols can be widely implemented at any MRI-capable radiologic department. However, before such a change to clinical practice can be implemented, it is necessary to demonstrate that hippocampal abnormalities on DWI are indeed very rare in the general population before attributing such abnormalities to TGA. This requires a controlled study in which patients with suspected TGA are compared to age-matched controls with identically protocoled imaging, including DWI with thin slices through the hippocampi and mesial temporal lobes. A positive diagnosis of patients with TGA by imaging criteria, rather than diagnosis by exclusion, would be useful in guiding clinicians considering further testing, such as EEG. It may also prove reassuring to patients, as TGA is benign and rarely recurs. 


\section{Study Funding}

No targeted funding reported.

\section{Disclosure}

A.V. Masurkar is on the council of the Alzheimer's Association International Grants Research Program and the steering committee of the Alzheimer's Disease Cooperative Study. Go to Neurology.org/N for full disclosures.

Appendix Authors

\begin{tabular}{lll}
\hline Name & Location & Contribution \\
\hline $\begin{array}{l}\text { Daniel } \\
\text { Talmasov, MD }\end{array}$ & $\begin{array}{l}\text { New York University } \\
\text { School of Medicine, New } \\
\text { York }\end{array}$ & $\begin{array}{l}\text { Manuscript preparation, } \\
\text { critical revision of } \\
\text { manuscript }\end{array}$ \\
\hline $\begin{array}{l}\text { Arjun V. } \\
\text { Masurkar, } \\
\text { MD, PhD }\end{array}$ & $\begin{array}{l}\text { New York University } \\
\text { York }\end{array}$ & $\begin{array}{l}\text { Manuscript preparation, } \\
\text { critical revision of } \\
\text { manuscript }\end{array}$ \\
\hline
\end{tabular}

\section{References}

1. Fisher CM, Adams RD. Transient global amnesia. Trans Amer Neurol Ass 1958: 143-146.

2. Pantoni L, Lamassa M, Inzitari D. Transient global amnesia: a review emphasizing pathogenic aspects. Acta Neurol Scand 2000;102:275-283.

3. Sedlaczek O, Hirsch JG, Grips E, et al. Detection of delayed focal MR changes in the lateral hippocampus in transient global amnesia. Neurology 2004;62:2165-2170.

4. Hodges JR, Warlow CP. Syndromes of transient amnesia: towards a classification: a study of 153 cases. J Neurol Neurosurg Psychiatry 1990;53: 834-843.

5. Hodges JR, Warlow CP. The aetiology of transient global amnesia: a casecontrol study of 114 cases with prospective follow-up. Brain 1990;113: 639-657.

6. Szabo K, Hoyer C, Caplan LR, et al. Diffusion-weighted MRI in transient global amnesia and its diagnostic implications. Neurology 2020;95: e206-e212.

7. Förster A, Al-Zghloul M, Wenz H, Böhme J, Groden C, Neumaier-Probst E. Isolated punctuate hippocampal infarction and transient global amnesia are indistinguishable by means of MRI. Int J Stroke 2017;12:292-296.

8. Michel P, Beaud V, Eskandari A, Maeder P, Demonet JF, Eskioglou E. Ischemic amnesia: causes and outcome. Stroke 2017;48:2270-2273.

9. Umemneku Chikere CM, Wilson K, Graziadio S, Vale L, Allen AJ. Diagnostic test evaluation methodology: a systematic review of methods employed to evaluate diagnostic tests in the absence of gold standard: an update. PLoS One 2019;14 $\mathrm{e} 0223832$.

10. Lanzone J, Ricci L, Assenza G, Ulivi M, Di Lazzaro V, Tombini M. Transient epileptic and global amnesia: real-life differential diagnosis. Epilepsy Behav $2018 ; 88: 205-211$. 


\section{Neurology}

\section{Journal Club: Diffusion-Weighted MRI in Transient Global Amnesia and Its Diagnostic Implications}

Daniel Talmasov and Arjun V. Masurkar

Neurology 2021;96;e2138-e2140 Published Online before print December 11, 2020

DOI 10.1212/WNL.0000000000011352

This information is current as of December 11, 2020

\section{Updated Information \&} Services

References

Subspecialty Collections

Permissions \& Licensing

Reprints including high resolution figures, can be found at: http://n.neurology.org/content/96/16/e2138.full

This article cites 9 articles, 4 of which you can access for free at: http://n.neurology.org/content/96/16/e2138.full\#ref-list-1

This article, along with others on similar topics, appears in the following collection(s):

\section{Cohort studies}

http://n.neurology.org/cgi/collection/cohort_studies

DWI

http://n.neurology.org/cgi/collection/dwi

Memory

http://n.neurology.org/cgi/collection/memory

Information about reproducing this article in parts (figures,tables) or in its entirety can be found online at:

http://www.neurology.org/about/about_the_journal\#permissions

Information about ordering reprints can be found online:

http://n.neurology.org/subscribers/advertise

Neurology ${ }^{\circledR}$ is the official journal of the American Academy of Neurology. Published continuously since 1951, it is now a weekly with 48 issues per year. Copyright @ 2020 American Academy of Neurology. All rights reserved. Print ISSN: 0028-3878. Online ISSN: 1526-632X.

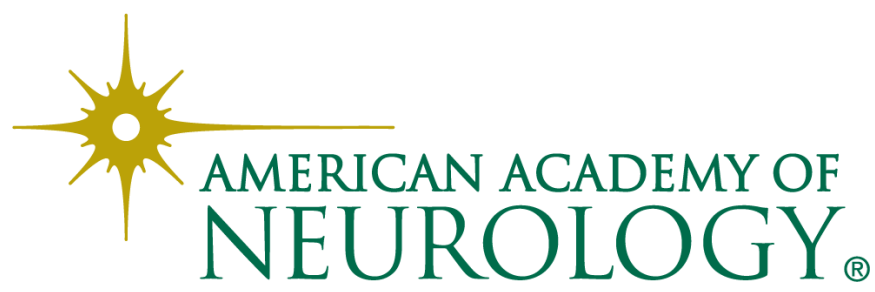

